ISSN 1045-6333

\title{
CORRUPTION AND OPTIMAL LAW ENFORCEMENT
}

\author{
A. Mitchell Polinsky \\ Steven Shavell
}

Discussion Paper No. 288

$7 / 2000$

\author{
Harvard Law School \\ Cambridge, MA 02138
}

The Center for Law, Economics, and Business is supported by a grant from the John M. Olin Foundation.

This paper can be downloaded without charge from:

The Harvard John M. Olin Discussion Paper Series: http://www.law.harvard.edu/programs/olin_center/ 


\title{
Corruption and Optimal Law Enforcement
}

\author{
A. Mitchell Polinsky ${ }^{\mathrm{a}, \mathrm{c}, *}$, Steven Shavell ${ }^{\mathrm{b}, \mathrm{c}}$ \\ ${ }^{a}$ Stanford Law School, Stanford, CA, USA

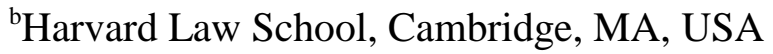 \\ 'National Bureau of Economic Research, Cambridge, MA, USA
}

\begin{abstract}
We analyze corruption in law enforcement: the payment of bribes to enforcement agents, threats to frame innocent individuals in order to extort money from them, and the actual framing of innocent individuals. Bribery, extortion, and framing reduce deterrence and are thus worth discouraging. Optimal penalties for bribery and framing are maximal, but, surprisingly, extortion should not be sanctioned. The state may also combat corruption by paying rewards to enforcement agents for reporting violations. Such rewards can partially or completely mitigate the problem of bribery, but they encourage framing. The optimal reward may be relatively low to discourage extortion and framing, or relatively high to discourage bribery.
\end{abstract}

Keywords: Corruption; Bribery; Extortion; Framing; Crime control

JEL classification: K14; K42

*Corresponding author: Stanford Law School, 559 Nathan Abbott Way, Stanford, CA 94305, USA. Tel.: (650) 723-0886; fax: (650) 723-3557. E-mail address:

polinsky@leland.stanford.edu 


\title{
Corruption and Optimal Law Enforcement
}

\author{
A. Mitchell Polinsky and Steven Shavell \\ (C) 2000 A. Mitchell Polinsky and Steven Shavell. All rights reserved.
}

\section{Introduction}

Our object in this article is to incorporate the possibility of corruption into the theory of optimal law enforcement. By corruption, we refer to the following phenomena. First, a law enforcement agent may engage in bribery, namely, he may accept a payment in return for not reporting a violation of law (or for reducing the mandated sanction for the violation). For example, in consideration of a bribe payment, a police officer may overlook a speeding violation, a building inspector may ignore a code infraction, or a detective may conceal evidence about a felony. Second, an enforcement agent may threaten to frame an innocent individual in order to extort money from him ${ }^{1}$ or may actually frame him. ${ }^{2}$

In Section 2, we analyze bribery, extortion, and framing assuming that the state does not attempt to control corruption, and our focus is on the basic question of why these forms of corruption are socially undesirable. The answer in essence is that they dilute deterrence of violations of law. Bribery dilutes deterrence because it results in a lower payment by an offender

${ }^{1}$ Cases in which an enforcement agent demands a payment from a violator also could be described as extortion, but we reserve that term to refer to instances in which the enforcement agent requests a payment in exchange for not framing an innocent person.

${ }^{2}$ Although we are not aware of any systematic data concerning the extent of corruption in law enforcement, such corruption is frequently reported in the press (for example, recent articles about framing involving members of the Los Angeles Police Department). Corruption in law enforcement is thought to be especially prevalent in developing countries. 
than the sanction for the offense. For example, suppose the bribe equals half of the fine and that the fine is $\$ 10,000$. Then offenders will pay bribes of $\$ 5,000$ instead of fines of $\$ 10,000 .^{3}$

Framing and extortion also dilute deterrence of violations of law. The reason is that framing and extortion imply that those who act innocently face an expected sanction, so that the difference between the expected sanction if individuals commit a violation and if they do not is lessened. Suppose offenders face an expected fine of $\$ 1,000$ and innocent individuals face an expected fine of $\$ 200$ due to the risk of being extorted or framed. Then the additional cost to an innocent individual of committing the offense is only $\$ 800$, whereas this cost would be $\$ 1,000$ if there were no risk of being extorted or framed.

Because corruption dilutes deterrence, its control may be socially desirable, and in section 3 we consider two ways to reduce corruption. One is to impose sanctions on individuals caught engaging in bribery, extortion, and framing. We demonstrate that the optimal fine for offenders and enforcers who engage in bribery is maximal, and that the optimal fine for enforcers who frame innocent individuals also is maximal. But, surprisingly, extortion should not be penalized, even though it is socially undesirable. The kernel of the reason is that sanctioning extortion will lead to one of two detrimental consequences: it will either fail to deter extortion and result in higher costs to innocent individuals (the sum of their expected extortion payment and the expected fine on them for paying extortion); or else it will cause enforcers to switch from

\footnotetext{
${ }^{3}$ The resulting dilution of deterrence could be offset if the fine could be raised to $\$ 20,000$, for then the bribe would be $\$ 10,000$, equal to the original fine that would be paid in the absence of corruption. In our model, however, it is not possible to raise the fine to offset the dilution of deterrence due to corruption because the optimal fine in the absence of corruption is maximal (for reasons explained below). In variations of our model, however, the optimal fine in the absence of corruption may be less than maximal, in which case there may be an opportunity to counter the effect of corruption by raising the fine, as we discuss in section 4 .
} 
extorting money from innocent individuals to framing them, which is socially worse. ${ }^{4}$

In section 3 we also discuss paying enforcers rewards for reporting violations. Such

payments will reduce their incentive to accept bribes because they will sacrifice their rewards if they fail to report violations. Indeed, sufficiently high rewards would eliminate all incentives to accept bribes. But high rewards may not be optimal because high rewards give enforcers a greater incentive to frame innocent individuals, and high rewards will tend to increase extortion payments (because enforcers sacrifice more by accepting the extortion payment). ${ }^{5}$ The optimal reward balances the beneficial effect of using rewards to offset the dilution of deterrence due to bribery with the detrimental effects associated with increased framing and extortion of innocent individuals.

In section 4, we conclude with several remarks about the assumptions and interpretation of our analysis. ${ }^{6}$

${ }^{4}$ We later discuss why, if various assumptions of our model are modified, it may be desirable to penalize extortion. See section 4 below.

${ }^{5}$ We discuss in section 4 other reasons why high rewards might not be desirable.

${ }^{6}$ Although there is a significant and growing literature on the economics of corruption, no one has undertaken a general welfare analysis of the two types of corruption - bribery on one hand, and framing/extortion on the other - and the use of both sanctions and rewards as means of control. Several articles, however, should be noted. Becker and Stigler (1974) focus on the control of bribery and consider paying rewards to enforcers or requiring them to post bonds. Mookherjee and Png (1995) restrict attention to bribery and conclude that bribery is optimal to eliminate, given their assumption that fines are unbounded. (In their analysis rewards are used induce enforcement agents to invest appropriate effort to detect violators.) Bowles and Garoupa (1997) also consider just bribery, and discuss its control through sanctions. Hindriks, Keen, and Muthoo (1999) study bribery and extortion in the context of tax evasion, and examine rewards and penalties as methods of control, but they do not undertake a general welfare analysis of corruption (their focus is on the extent of tax evasion and corruption, the tax revenue raised, and the distributional effects of the tax system). Other publications on corruption include Pashigian (1975), Klitgaard (1988), Shleifer and Vishny (1993), Bardhan (1997), and Rose-Ackerman (1999); many of these focus on corruption in the awarding of government contracts and licenses rather than corruption in the imposition of sanctions for violations of law. See also Tirole (1986) and Kofman and Lawarrée (1993) on collusion between parties in a multi-level principal and agent setting. 


\section{Why Corruption is Socially Undesirable}

In this section, we study bribery, extortion and framing in the absence of any attempt by the state to control corruption. In other words, we consider law enforcement in the absence of penalties on parties who engage in corruption or rewards to enforcers for reporting individuals. We do this in order to identify the social costs of corruption and thus explain why it may be optimal to control corruption. As noted in the introduction, we find that corruption is socially undesirable because it dilutes deterrence.

First consider the willingness of an offender and of an enforcer to enter into a bribe agreement after the offender has been detected by the enforcer. Let

$$
\begin{aligned}
& f=\text { fine imposed on the offender if an offense is reported; }{ }^{7} \\
& b=\text { bribe payment to an enforcer for not reporting an offense. }
\end{aligned}
$$

The offender will be willing to pay a bribe if $b<f,{ }^{8}$ and the enforcer will be willing to accept a bribe if $b>0$. Thus, there always exist mutually beneficial bribes such that $0<b<f$. We assume that a bribe will be made and accepted whenever there is a mutually beneficial bribe, so bribery will always occur. ${ }^{9}$

\footnotetext{
${ }^{7}$ For simplicity, we restrict attention to fines as sanctions. Were we to consider imprisonment, the general nature of our conclusions would not be altered.

${ }^{8}$ If $b=f$, the offender will be indifferent between paying a bribe and paying the fine; we assume for concreteness that bribery does not occur in this circumstance, and we adopt similar conventions elsewhere in this article.

${ }^{9}$ In making this assumption, we are abstracting from two reasons why bribery might not occur even when it would be mutually beneficial (analogous points apply to extortion). The first stems from the possibility that, after receiving a bribe payment, the enforcer still can threaten to report the offender and demand another payment. For instance, after discovering a health violation at a restaurant and being paid to keep quiet, an inspector might nonetheless threaten to disclose the violation. If the restaurant owner anticipates this threat, he would not pay a bribe in the first place (even though both he and the inspector would like to consummate a bribe agreement). However, this impediment to bribery can be overcome if either party can take an action that makes it difficult for the enforcer to provide a verifiable report of a violation (the inspector might agree not to gather evidence of the restaurant's
} 
We also assume that the bribe amount will be such that the parties' surplus from entering into a bribe agreement — the avoidance of the fine $f$ - is divided according to their relative bargaining power. Let

$$
\lambda=\text { bargaining power of the enforcer, } 0<\lambda<1 \text {, }
$$

so that the bribe amount is

$$
b=\lambda f
$$

Thus, the bribe increases with the fine. ${ }^{10}$

The incentive of an innocent individual to enter into an extortion agreement with an enforcer who could frame him is the same as that for a true offender to enter into a bribe agreement: in both cases the individual would bear the fine $f$ if reported. Thus, extortion will occur in response to a credible threat of framing, and the extortion amount is given by (1). Let $x=$ extortion payment to an enforcer for not reporting an innocent individual who could be framed.

The extortion payment then is:

$$
x=\lambda f
$$

violation or, if he has gathered evidence, to turn it over to the restaurant owner). Moreover, even if the enforcer could credibly threaten to report the offender after receiving a bribe payment, he may have a reputational interest in not doing so in order to encourage the payment of bribes in the future by that offender or others.

The second reason bribe agreements might not be reached is that asymmetry of information might lead the enforcer to misgauge the offender's willingness to pay a bribe or cause the offender to misjudge the enforcer's willingness to accept a bribe. For example, suppose the enforcer believes that the offender's level of wealth is much higher than it is. The offender might not be willing to offer a high bribe because he does not expect to pay much if he is turned in, but the enforcer might hold out for a substantial bribe, believing that the offender will otherwise bear a high fine. Similarly, asymmetry of information about the likelihood of a bribe being detected could lead to the failure of a bribe agreement. For expositional reasons, we abstract from issues of informational asymmetry in this article.

${ }^{10}$ One way to interpret (1) is that there is a probability $\lambda$ that the enforcer will be able to make a single demand to the offender, and a probability $(1-\lambda)$ that the offender will be able to make a single offer to the enforcer. Then $\lambda f$ is the expected bribe payment received by the enforcer. 
Next consider the decision of an individual to commit the harmful act. If he does so, he obtains a gain but faces a chance of being apprehended, in which case he will pay a bribe. If he does not commit the act, he faces a chance of being in circumstances in which he could be framed, in which case he will make an extortion payment. We suppose for simplicity that the probability that an innocent individual could be framed is a constant fraction of the probability that a true offender is detected. (This makes rough sense because the more enforcers there are, the greater the likelihood that an innocent individual could be framed.) Let

$$
\begin{aligned}
g= & \text { gain an individual obtains from committing the harmful act; } \\
p= & \text { probability of detecting offenders; } \\
\theta= & \text { ratio of the probability that an innocent individual could be framed } \\
& \text { to the probability that an offender is detected, } 0<\theta<1 .
\end{aligned}
$$

Hence, the probability that an innocent individual could be framed is $\theta p<p$. This characterization of the probability that an innocent individual could be framed guarantees that this probability is less than the probability that a true offender is detected. (Otherwise, unrealistically, individuals would have an incentive to commit an offense in order to reduce the chance of being subject to a sanction.)

Thus, if an individual commits the harmful act his expected payoff is $g-p b$, while he if does not commit the act his expected payoff is $-\theta p x$. Assuming risk neutrality, the individual will commit the harmful act if and only if $g-p b>-\theta p x$, or, equivalently, if and only if

$$
g>p b-\theta p x=(1-\theta) p \lambda f,
$$

where the latter equality follows from $b=x=\lambda f$.

We define the critical value of gain as the level of the gain below which an individual 
will not commit the harmful act and above which he will. Let

$$
\hat{g}=\text { critical value of gain. }
$$

Thus, from (3),

$$
\hat{g}=(1-\theta) p \lambda f
$$

It is clear from (4) that bribery lowers deterrence - that is, lowers $\hat{g}$ - for if bribery were absent the offender would pay $f$ rather than $\lambda f$. It also can be seen from (4) that the greater the chance that individuals can be framed - the higher is $\theta$ - the lower is $\hat{g}$. This makes sense because the greater the chance that an individual will be framed and pay extortion, the lower is the incremental cost to him of committing the harmful act. As observed in the introduction, it is the difference between the expected payment if the act is committed and if the act is not committed that determines the cost of committing the act; the higher is the chance of being framed and extorted, the lower is this difference. ${ }^{11}$

Note, too, that deterrence - the critical gain $\hat{g}$ - is increasing in the fine. This is true even though a higher fine raises the extortion payment as much as it raises the bribe payment. The reason deterrence increases is that the probability $p$ that an offender is detected exceeds the probability $\theta p$ that an innocent individual is extorted, so an increase in the fine causes the expected bribe payment borne by offenders to rise more than the expected extortion payment borne by innocent individuals. Hence, the incremental cost of committing the harmful act increases, which means that deterrence increases.

${ }^{11}$ The point that bribery lowers deterrence has been noted by Becker and Stigler (1974) and others. The point that framing and extortion reduce deterrence has not been observed previously, but is analogous to a point developed by Png (1986) in the context of the mistaken imposition of sanctions - that if innocent individuals are sanctioned by mistake, the difference between the expected sanction if the harmful act is committed and not committed declines. 
Social welfare is assumed to equal the gains that offenders derive from committing the harmful act, minus the harm they cause, and minus enforcement costs. Let

$$
\begin{aligned}
s(g) & =\text { density of gains among individuals, } s(g) \text { is positive on }[0, \infty){ }^{12} \\
h & =\text { harm from committing the act; } \\
c(p) & =\text { enforcement expenditure to detect offenders, } c_{p}>0 .
\end{aligned}
$$

Naturally, enforcement expenditures are increasing in the probability of apprehension.

Thus, social welfare can be expressed as:

$$
\int_{\hat{g}}^{\infty}(g-h) s(g) d g-c(p),
$$

where $\hat{g}$ is given by (4). ${ }^{13}$ The social problem is to choose the fine $f$ (which enters (5) through $\hat{g}$ ) and the probability of apprehension $p$ to maximize (5). Optimal values of these variables are indicated by an asterisk, and we presume here and in subsequent sections that $p *$ is positive (otherwise the issue of bribery and extortion would not arise).

We assume that the fine is bounded by the offender's level of wealth, and that this level is the same for all offenders. Let

$$
w_{O}=\text { wealth of an offender. }
$$

Note that in assuming that $f$ is at most $w_{O}$, we are implicitly presuming, for simplicity, that the gain to an offender does not increase his capacity to pay a fine (as would be the case, for

\footnotetext{
12 The density of gains among individuals is assumed to be known to the state, but not the gain obtained by a particular individual.

${ }^{13}$ Social welfare can be expressed in this way because, if individuals are risk neutral, bribes, extortion payments, and fines are all merely transfers of money and therefore do not affect social welfare. Also, we are abstracting from the deadweight burden of any taxes needed to raise money to finance enforcement, and from the reduction in the deadweight burden resulting from the collection of fines. (Analogous observations apply in section 3 regarding the payment of rewards to enforcers.)
} 
example, if the gain is in utility).

First observe that, as in the enforcement problem in the absence of corruption, the optimal fine equals the maximum feasible fine, $w_{O} \cdot{ }^{14}$ The explanation is the usual one that is associated with Becker (1968). Namely, if the fine were not maximal, it could be raised and the probability of detection lowered without affecting deterrence (even though bribes and extortion payments may be altered), but saving enforcement costs; thus a fine that is not maximal would not be optimal. To see this formally, assume that $f$ is less than $w_{O}$ and that $p$ is positive. Raise $f$ to $w_{O}$ and lower $p$ to a level $p^{\prime}$ such that $p^{\prime} w_{O}=p f$. It is clear from (4) that $\hat{g}$ does not change, and it is clear from (5) that the only effect on social welfare is that $c(p)$ declines, which raises social welfare. Hence, $f^{*}=w_{O}$.

The optimal probability is then determined by maximizing (5) over $p$, with $f=w_{O}$. Because the characterization of $p^{*}$ is not especially relevant to the analysis of corruption in law enforcement, we omit the details here. ${ }^{15}$

We now state the results that can be demonstrated about corruption in the preceding model.

PROPOSITION 1. If the state does not attempt to control corruption, then:

(a) bribery will occur whenever an offender is apprehended by an enforcement agent;

(b) extortion will occur whenever an innocent individual is in a situation in which he can

${ }^{14}$ See, for example, Polinsky and Shavell (2000, p. 53) on the standard result that the fine should be maximal when individuals are assumed to be risk neutral. The explanation of this result is essentially that given in the remainder of the present paragraph in the text.

${ }^{15}$ The optimal probability when corruption is possible bears no necessary relationship to the optimal probability in the absence of corruption. In particular, $p^{*}$ might be higher to offset the deterrence-diluting effects of corruption, or $p^{*}$ might be lower because the deterrence-diluting effects of corruption reduce the efficacy of expenditures on detection. 
be framed; and

(c) bribery and extortion lower social welfare relative to the situation in which they are absent, due to their deterrence-diluting effects.

PROOF: Parts (a) and (b): These parts were explained above.

Part (c): Let $p$ and $f$ be the probability of detection and the fine when corruption occurs, in which case the critical gain is $\hat{g}=(1-\theta) p \lambda f$. If corruption were absent, the critical gain would rise to $p f$. Then lower the probability to $p^{\prime}=(1-\theta) p \lambda$ and keep the fine at $f$, so that the critical gain in the absence of corruption is $\hat{g}^{\prime}=p^{\prime} f=(1-\theta) p \lambda f=\hat{g}$. It is obvious from (5) that the only effect on social welfare is to lower enforcement costs because $p^{\prime}<p$. Thus, social welfare is higher without corruption.

We explained in the introduction, and showed formally above, why corruption dilutes deterrence: bribery leads to a lower payment by an offender than the sanction for the offense; and framing and extortion result in innocent individuals bearing an expected payment, lessening the cost of committing the violation. If corruption could be eliminated, therefore, deterrence would be higher; and if deterrence were higher, the probability of detection could be lowered until the level of deterrence declines to the level with corruption, thereby saving enforcement costs. This, in essence, is the logic behind part (c) of Proposition 1.

The results of this section can be illustrated with a numerical example. Let the harm $h$ be $\$ 1,500$; the gain $g$ that individuals obtain from committing the harmful act be distributed uniformly between $\$ 0$ and $\$ 2,000$; the enforcement expenditure $c$ required to detect violators with probability $p$ be $\$ 10,000 p^{2}$; the wealth of offenders $w_{O}$ be $\$ 10,000$; the bargaining power of the enforcer $\lambda$ be .7 ; and the ratio of the probability that an innocent individual could be framed 
to the probability that an offender is detected $\theta$ be .3. The first-best outcome then is for individuals to commit the harmful act if and only if their gains exceed $\$ 1,500$ - that is, for the critical gain $\hat{g}$ to be $\$ 1,500$. If corruption were absent, the optimal fine $f^{*}$ would be $\$ 10,000$ and the optimal probability of detecting offenders $p^{*}$ would be .11 , resulting in $\hat{g}$ equal to $\$ 1,100$ $(=.11 \times \$ 10,000)$ and social welfare equal to $-\$ 98 .{ }^{16}$ If corruption occurs, $f^{*}$ remains at $\$ 10,000, p^{*}$ remains at $.11, \hat{g}$ falls by more than half to $\$ 539(=(1-.3) \times .11 \times .7 \times \$ 10,000)$, and social welfare declines to $-\$ 289$. The reduction in social welfare is due, of course, to the dilution of deterrence resulting from corruption. Instead of paying a fine of $\$ 10,000$, offenders who are detected now pay a bribe of $\$ 7,000$. In addition, innocent individuals face a probability of $.033(=.3 \times .11)$ of being in a situation in which they could be framed, in which case they make an extortion payment of $\$ 7,000$. Consequently, the cost of becoming an offender is reduced by $\$ 231(=.033 \times \$ 7,000)$.

\section{Controlling Corruption with Sanctions and Rewards}

In this section we introduce the possibility of detecting and sanctioning corruption, as well as rewarding enforcers who report offenders to the state. As discussed in the introduction, we show that optimal fines for bribery and framing are maximal, but that extortion should not be sanctioned; and we demonstrate that the optimal reward may be relatively low to discourage extortion and framing, or relatively high to discourage bribery.

We now suppose that if an offender is detected by an enforcement agent and pays a bribe

\footnotetext{
${ }^{16} \mathrm{We}$ calculated social welfare for values of $p$ in increments of .01 from .01 to 1. (Analogous procedures are used in section 3 when we consider other policy instruments - the reward paid to enforcers and the probabilities of detecting bribery, framing, and extortion.) 
to him to avoid paying the fine $f$, the bribe might then be discovered, resulting in imposition of a fine on both the offender and the enforcer. ${ }^{17}$ Let

$$
\begin{aligned}
f_{O B} & =\text { fine imposed on an offender who is caught engaging in bribery; } \\
f_{E B} & =\text { fine imposed on an enforcer who is caught engaging in bribery; } \\
q_{B} & =\text { probability of detecting bribery; } \\
c_{B}\left(q_{B}\right) & =\text { enforcement cost to detect bribery, } c_{B}\left(q_{B}\right)>0 .
\end{aligned}
$$

We assume that if bribery is detected, the bribe transaction is undone before fines for bribery are imposed. ${ }^{18}$ We also assume that an offender who pays a bribe and thereafter is caught does not also pay the fine $f$ for the offense (there is no loss of generality in making this assumption because $f_{O B}$ can equal or exceed $f$ ).

Also, let

$r$ = reward to the enforcer if an offender is reported.

If an offender who has been detected does not offer a bribe, he pays $f$. If he offers a bribe, he pays $b$ and faces the probability $q_{B}$ that the bribe will be discovered, in which case the bribe transaction will be undone and he will have to pay a fine $f_{O B}$. Thus, a detected offender will prefer to pay a bribe if and only if

$$
\left(1-q_{B}\right) b+q_{B} f_{O B}<f
$$

Similarly, the enforcer will accept a bribe if and only if

${ }^{17}$ For simplicity, we assume that the enforcers hired to detect bribery are not themselves subject to bribery. For a discussion of bribery when the enforcers who detect bribery are corruptible, see Basu, Bhattacharya, and Mishra (1992).

${ }^{18}$ If the bribe transaction were not undone, the offender's ability to pay a fine for engaging in bribery would decline by the amount of the bribe, and the enforcer's ability to pay a fine would increase by the amount of the bribe. Then we would have to deal with the distracting complication that the bribe payment would itself affect the magnitude of the fines that could be paid for bribery. 


$$
\left(1-q_{B}\right) b-q_{B} f_{E B}>r .
$$

For a bribe to be feasible, (6) and (7) imply that

$$
\left(r+q_{B} f_{E B}\right) /\left(1-q_{B}\right)<b<\left(f-q_{B} f_{O B}\right) /\left(1-q_{B}\right) .
$$

As before, we assume that if a mutually beneficial bribe exists, it will be made. ${ }^{19}$ It

follows from (8) that a bribe will be made if and only if $r+q_{B} f_{E B}<f-q_{B} f_{O B}$, or equivalently, if and only if:

$$
q_{B}\left(f_{O B}+f_{E B}\right)<f-r .
$$

The interpretation of (9) is that bribery will occur if and only if the expected sum of fines for bribery is less than the parties' surplus from entering into a bribe agreement (the surplus is the avoidance of the fine $f$ less the forgone reward $r$ ). Hence, bribery can be deterred if the expected sum of fines for bribery is sufficiently high or if the reward to the enforcer for reporting an offender is sufficiently high. Specifically in the latter case, if

$$
r \geq f-q_{B}\left(f_{O B}+f_{E B}\right),
$$

then (9) does not hold and bribery will not occur. Let

$$
r_{B}=\text { the reward at or above which bribery is deterred. }
$$

Thus,

$$
r_{B}=f-q_{B}\left(f_{O B}+f_{E B}\right) .
$$

If bribery is deterred, the enforcer will turn in the offender in order to obtain the reward.

When bribery occurs, the enforcer obtains a fraction $\lambda$ of the parties' surplus from

${ }^{19}$ There is a potential impediment to bribery analogous to one that was discussed above in note 9 . After making a bribe payment, the offender might be able to threaten to expose the enforcer for having taken a bribe unless the enforcer returns some or all of it. If the enforcer expects this to happen, he might not accept the bribe initially. This obstacle to reaching a bribe agreement can be circumvented if the parties can ensure that there is no record of the bribe payment. 


$$
b=\left\{r+q_{B} f_{E B}+\lambda\left[(f-r)-q_{B}\left(f_{O B}+f_{E B}\right)\right]\right\} /\left(1-q_{B}\right) .
$$

The interpretation of (12) is that the offender must compensate the enforcer for the forgone reward and for bearing an expected fine of $q_{B} f_{E B}$, as well as give him a fraction $\lambda$ of the surplus from bribery.

The incentive of an innocent individual who could be framed to enter into an extortion agreement with an enforcer now differs from the incentive of a true offender to enter into a bribe agreement. Let

$$
\begin{aligned}
f_{I X}= & \text { fine imposed on an innocent individual who is caught paying } \\
& \text { extortion; } \\
f_{E X} & =\text { fine imposed on an enforcer who is caught engaging in extortion; } \\
f_{E F} & =\text { fine imposed on an enforcer who is caught engaging in framing; } \\
q_{X} & =\text { probability of detecting extortion; } \\
q_{F} & =\text { probability of detecting framing; } \\
c_{X}\left(q_{X}\right) & =\text { enforcement cost to detect extortion, } c_{X}{ }^{\prime}\left(q_{X}\right)>0 ; \\
c_{F}\left(q_{F}\right) & =\text { enforcement cost to detect framing, } c_{F}{ }^{\prime}\left(q_{F}\right)>0 .{ }^{20}
\end{aligned}
$$

We assume that if extortion is detected, the extortion transaction is undone before fines for extortion are imposed. Similarly, if framing is detected, the reward to the enforcer is returned to the state before a fine for framing is imposed on the enforcer. ${ }^{21}$

First observe that an innocent individual will not pay anything to the enforcer unless the

\footnotetext{
${ }^{20}$ In order to understand the possible desirability of using different enforcement policies to control bribery, extortion, and framing, we assume that the detection of each of these forms of corruption is an independent activity with its own cost function.

21 These assumptions are analogous to the one made in note 18 above, and are made for the same reason.
} 
enforcer's threat to turn him in is credible. If the enforcer reports the individual, the enforcer obtains the reward $r$ with probability $1-q_{F}$, but with probability $q_{F}$ he will be caught and made to pay a fine $f_{E F}$. Thus, the enforcer will be willing to turn in an innocent individual if and only if (1 $\left.-q_{F}\right) r$ exceeds $q_{F} f_{E F}$, that is, if and only if ${ }^{22}$

$$
r>q_{F} f_{E F} /\left(1-q_{F}\right)
$$

Let

$$
r_{F}=\text { the reward at or below which framing is deterred. }
$$

Therefore,

$$
r_{F}=q_{F} f_{E F} /\left(1-q_{F}\right) .
$$

Assuming (13) holds, if the innocent individual does not pay extortion he will be reported and pay $f$, but with probability $q_{F}$ the enforcement authority will determine that he was framed and return the fine payment to him. If instead he pays extortion, he pays $x$ and will be detected with probability $q_{X}$, in which case the extortion transaction will be undone and he will have to pay a fine $f_{I X}$ (which could be zero). Thus, an innocent individual who is subject to a credible threat of being framed would prefer to pay extortion if and only if

$$
\left(1-q_{X}\right) x+q_{X} f_{I X}<f-q_{F} f=\left(1-q_{F}\right) f .
$$

Similarly, if the enforcer accepts the extortion payment, he obtains $x$ and faces the probability $q_{X}$ of having the extortion transaction undone and paying a fine $f_{E X}$. If instead the

\footnotetext{
${ }^{22}$ Note that we are assuming here that if the enforcer is indifferent between framing an innocent individual and not framing him, he will not frame the individual. In the previous section, however, we implicitly assumed that if the enforcer is indifferent, he will frame the individual. We alter this assumption in the present section to avoid a technical problem that would require us to make a distracting and inessential qualification to the statement of our main proposition. In particular, if an indifferent enforcer would frame an innocent individual, then the optimal reward $r^{*}$ may not exist. Instead, it may be that the closer $r$ is to $q_{F} f_{E F} /\left(1-q_{F}\right)$, the higher is social welfare, but if $r=$ $q_{F} f_{E F} /\left(1-q_{F}\right), r$ is suboptimal. By making the assumption we do here, $r^{*}=q_{F} f_{E F} /\left(1-q_{F}\right)$ in this case (see part (h) of Proposition 2).
} 
enforcer turns in the innocent individual, he obtains the reward $r$ but faces the probability $q_{F}$ that he will be caught, in which case he will forfeit the reward and pay a fine $f_{E F}$. Hence, he will accept an extortion payment if and only if

$$
\left(1-q_{X}\right) x-q_{X} f_{E X}>\left(1-q_{F}\right) r-q_{F} f_{E F} .
$$

Therefore, for extortion to be feasible, (15) and (16) imply that

$$
\left(\left(1-q_{F}\right) r+q_{X} f_{E X}-q_{F} f_{E F}\right) /\left(1-q_{X}\right)<x<\left(\left(1-q_{F}\right) f-q_{X} f_{I X}\right) /\left(1-q_{X}\right) .
$$

It follows from (17) that an extortion payment will be made if and only if

$$
q_{X}\left(f_{I X}+f_{E X}\right)<\left(1-q_{F}\right) f-\left(\left(1-q_{F}\right) r-q_{F} f_{E F}\right) .
$$

The interpretation of (18) is analogous to that of (9): extortion will occur if and only if the expected sum of fines for extortion is less than the surplus from entering into an extortion agreement (the surplus is the avoidance of the expected fine for the offense, $\left(1-q_{F}\right) f$, less the expected reward net of the enforcer's expected fine for engaging in framing, $\left.\left(1-q_{F}\right) r-q_{F} f_{E F}\right)$. Thus, extortion can be deterred if the expected sum of fines for extortion is sufficiently high or if the reward to the enforcer for reporting an offender is sufficiently high, specifically if

$$
r \geq\left[\left(1-q_{F}\right) f-q_{X}\left(f_{I X}+f_{E X}\right)+q_{F} f_{E F}\right] /\left(1-q_{F}\right)
$$

Let

$$
r_{E}=\text { the reward at or above which extortion is deterred. }
$$

Hence,

$$
r_{E}=\left[\left(1-q_{F}\right) f-q_{X}\left(f_{I X}+f_{E X}\right)+q_{F} f_{E F}\right] /\left(1-q_{F}\right)
$$

Note that if extortion is deterred, the enforcer will turn in the innocent individual in order to obtain the reward (assuming, as we have in this discussion, that the enforcer's threat to frame is credible). 
When extortion occurs, the enforcer obtains a fraction $\lambda$ of the parties' surplus from entering into the extortion agreement. Using (17), the extortion payment is

$$
x=\left\{\left(1-q_{F}\right) r+q_{X} f_{E X}-q_{F} f_{E F}+\lambda\left[\left(1-q_{F}\right)(f-r)-q_{X}\left(f_{I X}+f_{E X}\right)+q_{F} f_{E F}\right]\right\} /\left(1-q_{X}\right) .
$$

Next consider an individual's decision whether to commit the harmful act, which can be characterized by his critical level of gain $\hat{g}$ (above which he will commit the act and below which he will not). To derive $\hat{g}$, it will be useful to define the following notation:

$$
\begin{aligned}
& z_{O}=\text { expected payment of an offender; and } \\
& z_{I}=\text { expected payment of an innocent individual. }
\end{aligned}
$$

Suppose first that $r \leq r_{F}$, so the enforcer does not have a credible threat to frame an innocent individual. Then, $\hat{g}=z_{0}$, where

$$
z_{O}=\min \left\{p f, p\left[\lambda f+(1-\lambda)\left[r+q_{B}\left(f_{O B}+f_{E B}\right)\right]\right]\right\} .
$$

This follows because an offender is detected with probability $p$; if he is detected, he will pay the fine or, if a mutually beneficial bribe exists, a bribe. In the latter case, his expected payment is (1 $\left.-q_{B}\right) b+q_{B} f_{O B}$, for with probability $q_{B}$ the offender is caught engaging in bribery, has the bribe transaction undone, and pays a fine $f_{O B}$. Using (12), this can be written as the term in brackets on the right-hand side of the min expression in (22).

Next suppose that $r>r_{F}$, so the enforcer does have a credible threat to frame an innocent individual. Then $\hat{g}=z_{O}-z_{I}$, where $z_{O}$ is given by (22) and

$$
z_{I}=\min \left\{\theta p\left(1-q_{F}\right) f, \theta p\left[\lambda\left(1-q_{F}\right) f+(1-\lambda)\left[\left(1-q_{F}\right) r+q_{\mathrm{X}}\left(f_{I X}+f_{E X}\right)-q_{F} f_{E F}\right]\right]\right\} .
$$

This follows because an innocent individual will be in circumstances in which he might be framed with probability $\theta p$; if he is in such circumstances, he will pay the fine or, if a mutually beneficial extortion payment exists, extortion. If he pays the fine, the fine payment will be 
returned to him if framing is discovered, which occurs with probability $q_{F}$, so his expected fine payment is $\left(1-q_{F}\right) f$. If he pays extortion, his expected payment is $\left(1-q_{X}\right) x+q_{X} f_{I X}$, for reasons analogous to those discussed following (22). Using (21), this can be written as the term in the outer brackets on the right-hand side of the min expression in (23).

Social welfare now is

$$
\int_{\hat{g}}^{\infty}(g-h) s(g) d g-c(p)-c_{B}\left(q_{B}\right)-c_{X}\left(q_{X}\right)-c_{F}\left(q_{F}\right),
$$

where $\hat{g}=z_{O}$ if $r \leq q_{F} f_{E F} /\left(1-q_{F}\right)$, and $\hat{g}=z_{O}-z_{I}$ if $r>q_{F} f_{E F} /\left(1-q_{F}\right)$. The social problem is to maximize (24) over the reward, the fines, and the probabilities of detection.

The fines on the offender for the offense and for engaging in bribery are bounded by the offender's level of wealth, $w_{O}$. We assume that innocent individuals have the same level of wealth as offenders, so the fine on them for paying extortion is bounded by $w_{O}$. The fines on the enforcer for engaging in extortion or framing are bounded by the enforcer's level of wealth; let $w_{E}=$ wealth of an enforcer.

As in section 2, the optimal fine for the offense, $f^{*}$, equals the maximum feasible fine, $w_{O}$. The proof of this claim, which is now more complicated because of the need to consider sanctions for corruption and rewards to enforcers, is deferred to the paragraph following the proof of Proposition 2 below. We omit discussion here of the optimal probability of detection $p^{*}$, again because the characterization of $p^{*}$ does not bear on the analysis of corruption in law enforcement.

We now state the results that can be demonstrated about corruption.

PROPOSITION 2. If corruption is controlled both by sanctioning it and rewarding enforcers, 
then:

(a) for true offenders, bribery will occur if the expected sum of fines for bribery, $q_{B}\left(f_{O B}+\right.$ $f_{E B}$ ), is less than the fine on the offender minus the reward to the enforcer, $f-r$, which is the parties' surplus from entering into a bribe agreement; if the expected sum of fines for bribery equals or exceeds this amount, offenders will be turned in;

(b) for innocent individuals, extortion or framing will occur if and only if an enforcer has a credible threat to frame, that is, if and only if the expected reward $\left(1-q_{F}\right) r$ paid to the enforcer exceeds his expected fine for framing, $q_{F} f_{E F}$ - equivalently, if and only if $r>r_{F}=q_{F} f_{E F} /\left(1-q_{F}\right)$, where $r_{F}$ is the reward at or below which framing is deterred;

(c) provided that the enforcer's threat to frame is credible, extortion will occur if the expected sum of fines for extortion, $q_{X}\left(f_{I X}+f_{E X}\right)$, is less than the expected fine for the offense minus the expected reward net of the enforcer's expected fine for engaging in framing, $\left(1-q_{F}\right) f$ $\left(\left(1-q_{F}\right) r-q_{F} f_{E F}\right)$, which is the parties' surplus from entering into an extortion agreement; if the expected sum of fines for extortion equals or exceeds this amount, innocent individuals will be framed;

(d) the optimal fines for bribery and framing are maximal: $f_{O B} *=w_{O}$, and $f_{E B} *=f_{E F} *=w_{E}$;

(e) the optimal probability of detecting bribery $q_{B}{ }^{*}$ is in the interval $\left[0, \bar{q}_{B}\right]$, where $\bar{q}_{B}=$ $(f-r) /\left(f_{O B}+f_{E B}\right)<1$ is the lowest probability of detecting bribery that deters bribery;

(f) the optimal probability of detecting framing $q_{F} *$ is in the interval $\left[0, \bar{q}_{F}\right]$, where $\overline{q_{F}}=$ $r /\left(r+f_{E F}\right)<1$ is the lowest probability of detecting framing that deters framing;

(g) the optimal probability of detecting extortion is zero: $q_{X}^{*}=0$; and

(h) the optimal reward to the enforcer $r^{*}$ either equals $r_{F}=q_{F} f_{E F} /\left(1-q_{F}\right)$, the reward at or 
below which framing is deterred, or $r_{B}=f-q_{B}\left(f_{O B}+f_{E B}\right)$, the reward at or above which bribery is deterred; if $r^{*}$ equals $r_{F}$, enforcers' threats to frame are not credible and framing and extortion are deterred, but bribery occurs; if $r^{*}$ equals $r_{B}$, bribery is deterred, but enforcers' threats to frame are credible and extortion occurs; $r_{F}$ is less than or equal to $r_{B}{ }^{23}$

PROOF: Parts (a), (b), and (c): These parts were demonstrated above; see (9), (13), and (18), respectively.

Part (d): To establish that $f_{O B} *$ is maximal, assume otherwise, that $f_{O B} *<w_{O}$, and raise $f_{O B}$ to $w_{O}$. This does not affect $z_{I}$ but does increase the right-hand side of the min expression for $z_{0}$; see (22). It is clear that $q_{B}$ can be lowered so as to restore the right-hand side of the min expression to its level at the original $f_{O B}$. Hence, $\hat{g}$ and the behavior of individuals will be unchanged when $f_{O B}$ is raised and $q_{B}$ lowered, so that the integral term in social welfare (24) is unchanged, but social welfare rises because enforcement costs to detect bribery $c_{B}\left(q_{B}\right)$ fall. Consequently, $f_{O B}{ }^{*}=w_{O}$. Analogous logic implies that $f_{E B} *=w_{E}$.

To show that $f_{E F} *$ is maximal, assume that $f_{E F} *<w_{E}$ and raise $f_{E F}$ to $w_{E}$. We will demonstrate that social welfare either remains the same or rises. There are three cases to consider. First, the condition for the enforcer's threat to frame to be credible (13) may hold both at the original $f_{E F}$ as well as at $w_{E}$. Then $\hat{g}=z_{O}-z_{I}$ at both $f_{E F}$ and $w_{E}$. The only effect of raising $f_{E F}$ to $w_{E}$ is to lower the right-hand side of the min expression for $z_{I}(23)$. If the left-hand side of the min expression remains lower than the right-hand side, then $\hat{g}$ is unaffected and social welfare is unaffected. If the right-hand side becomes lower as a result of raising $f_{E F}$, then $z_{I}$ declines and $\hat{g}$ rises; if $p$ is then lowered to restore $\hat{g}$ to its original value (that this can be done is

\footnotetext{
${ }^{23}$ If $r^{*}=r_{F}=r_{B}$, then both framing and bribery are deterred.
} 
clear from inspecting (22) and (23)), social welfare rises because the integral term in social welfare (24) is unchanged but enforcement costs to detect the offense $c(p)$ fall.

In the second case, the threat to frame is credible - (13) holds - at the original $f_{E F}$ but not at $w_{E}$. Then $\hat{g}=z_{O}-z_{I}$ at $f_{E F}$ and $\hat{g}=z_{O}$ at $w_{E}$. Because $z_{O}$ is unaffected by raising $f_{E F}$ (see (22)), $\hat{g}$ clearly rises. Hence, $p$ again can be lowered to restore $\hat{g}$ to its original value, resulting in an increase in social welfare.

Finally, (13) may not hold at the original $f_{E F}$, in which case it also will not hold at $w_{E}$. Then $\hat{g}=z_{O}$ at both $f_{E F}$ and $w_{E}$. Because raising $f_{E F}$ to $w_{E}$ raises the right-hand side of (13), $q_{F}$ can be lowered so as to leave the right-hand side of (13) unchanged, so (13) will continue to not hold at the lower $q_{F}$. Social welfare therefore rises because $\hat{g}$ is unaffected but enforcement costs to detect framing $c_{F}\left(q_{F}\right)$ fall. Together, these three cases imply that $f_{E F} *=w_{E}$.

Part (e): To demonstrate the claim about $q_{B}{ }^{*}$, note that, from (9), any $q_{B}$ equal to or exceeding $\left.\bar{q}_{B}=(f-r) /\left(f_{O B}+f_{E B}\right)\right]$ deters bribery. Hence, behavior will be the same if $q_{B}$ is lowered to $\bar{q}_{B}$, but enforcement costs to detect bribery $c_{B}\left(q_{B}\right)$ will fall, so social welfare will rise. Thus, $q_{B}{ }^{*}$ must be less than or equal to $\bar{q}_{B}$. That $\bar{q}_{B}$ is less than one follows from the fact that $f^{*}=f_{O B} *$ $=w_{O}$.

Part (f): To prove the result about $q_{F}{ }^{*}$, note that any $q_{F}$ equal to or exceeding $\overline{q_{F}}=r /(r+$ $f_{E F}$ ) will, by (13), deter framing and extortion, so behavior will be the same as if $q_{F}$ is $\bar{q}_{F}$. However, enforcement costs to detect framing $c_{F}\left(q_{F}\right)$ will fall, so social welfare will rise. Thus, $q_{F} *$ cannot exceed $\bar{q}_{F}$. That $\bar{q}_{F}$ is less than one follows from the fact that $f_{E F} *=w_{E}$.

Part (g): To prove that $q_{\mathrm{X}}{ }^{*}=0$, first suppose that (13) does not hold - there is not a credible threat to frame. In this case, $q_{\mathrm{x}}=0$ must be optimal because it lowers enforcement costs 
relative to a positive $q_{\mathrm{X}}$, and does not affect behavior because there is no extortion. Next, suppose that (13) does hold. Then $\hat{g}=z_{O}-z_{I}$ and $q_{\mathrm{X}}$ affects $\hat{g}$ through $z_{I}$; the lower is $q_{\mathrm{X}}$, the lower is the right-hand side of the min condition in (23). This either has no effect on $z_{I}$ (if the left-hand side of the min condition in (23) is lower than the right-hand side) or lowers $z_{I}$ (if the right-hand side of the min condition is lower). Thus, the critical gain $\hat{g}$ either remains the same or increases. If $\hat{g}$ remains the same, social welfare rises because $c_{X}\left(q_{X}\right)$ declines. If $\hat{g}$ rises, social welfare rises both because $c_{X}\left(q_{X}\right)$ declines and because $p$ can be lowered without sacrificing deterrence. Hence, $q_{X}{ }^{*}=0$.

Part (h): We want to prove that $r^{*}$ is equal to $r_{F}$ or $r_{B}$ and that $r_{F} \leq r_{B}$. It is obvious, moreover, that $r_{B}<r_{E}\left(r_{B}\right.$ is less than $f$ and $r_{E}$ is greater than $\left.f\right)$.

Suppose first that $r_{B}<r_{F}$ at the optimal solution to the enforcement problem. We will demonstrate that this cannot be true, because if it were, social welfare could be raised by lowering $q_{F}$, and thereby lowering $r_{F}$, contradicting the assumption that $r_{B}<r_{F}$ is optimal. We will do this in several steps. (1) First observe that $r^{*}$ cannot be less than $r_{B}$. If $r<r_{B}$, bribery would occur but there would not be a credible threat to frame. Hence, if $r$ is raised to $r_{B}, \hat{g}=z_{O}$ rises (the right-hand side of (22) is applicable and rising in $r$ up to $r_{B}$ ). Then $p$ can be lowered so as to restore $\hat{g}$ to its original level, so the integral term in social welfare (24) will be constant, but social welfare will rise because $c(p)$ falls. Thus, $r^{*}$ must be equal to or greater than $r_{B}$. (2) Next observe that $r^{*}$ cannot exceed $r_{F}$. If $r>r_{F}$, bribery would not occur but the enforcer would have a credible threat to frame. Hence, if $r$ is lowered to $r_{F}, \hat{g}$ rises from $z_{O}-z_{I}$ to $z_{O}$ (where $z_{O}$ is given by the left-hand side of (22) since $r$ exceeds $r_{B}$ ). Then, as in step 1, $p$ can be lowered so as to raise social welfare. Hence, $r^{*}$ must be equal to or less than $r_{F}$. (3) The previous steps imply 
that $r *$ is in the interval $\left[r_{B}, r_{F}\right]$. We next claim that all $r$ in this interval lead to the same level of social welfare, and hence $r^{*}$ can be taken to be any $r$ in the interval $\left[r_{B}, r_{F}\right]$. To show this, note that for any $r$ in this interval, there is neither bribery nor a credible threat to frame - so offenders are reported and fined, and innocent parties do not pay anything. Hence, $\hat{g}=z_{O}=p f$, and $r$ has no influence on social welfare. (4) Now observe that social welfare can be raised by lowering $q_{F}$. We know that $r^{*}$ can be taken to be any $r$ in the interior of the interval $\left[r_{B}, r_{F}\right]$, so choose some such $r^{*}$. Then reduce $q_{F}$ slightly. This will result in a new $r_{F}{ }^{\prime}<r_{F}$ that still exceeds $r^{*}$. Hence, $\hat{g}$ is not affected, but social welfare will rise because $c_{F}\left(q_{F}\right)$ is lower. (5) The previous steps establish that $r_{F} \leq r_{B}$. We next claim that $r^{*}$ cannot be less than $r_{F}$. If $r<r_{F}$, there would not be a credible threat to frame but bribery would occur, so that, as in step 1, raising $r$ raises $\hat{g}=$ $z_{O}$ and allows social welfare to be increased by lowering $p$. (6) In addition, $r^{*}$ cannot exceed $r_{B}$. If $r \geq r_{E}>r_{B}$, bribery would not occur but framing would, so $\hat{g}=z_{O}-z_{I}=p f-\theta p\left(1-q_{F}\right) f$, which does not depend on $r$. Hence, any $r \geq r_{E}$ results in the same level of social welfare. If $r_{E}>r>r_{B}$, bribery is deterred but extortion is not, so $\hat{g}=p f-z_{I}$, where $z_{I}$ is given by the right-hand side of (23)). Lowering $r$ lowers $z_{I}$ and thereby raises $\hat{g}$, so social welfare can be increased by lowering $p$. It also is clear that $\hat{g}$ is higher when $r_{E}>r>r_{B}$ than when $r \geq r_{E}\left(z_{O}\right.$ is the same in both cases, but $z_{I}$ is lower in the former case because innocent individuals are hurt less by extortion than by framing). Thus, $r^{*}$ must be equal to or less than $r_{B}$. (7) We next claim that $r^{*}$ cannot be in $\left(r_{F}\right.$, $\left.r_{B}\right)$. To prove this, note that if $r$ is in $\left(r_{F}, r_{B}\right)$, bribery and extortion occur (because $r_{F}<r<r_{B}<$ $r_{E}$ ), so $\hat{g}=z_{O}-z_{I}$, where $z_{O}$ is given by the right-hand side of (22) and $z_{I}$ is given by the righthand side of (23). The derivative of $\hat{g}$ with respect to $r$ is $p(1-\lambda)\left[1-\theta\left(1-q_{F}\right)\right]$, which clearly is positive. Thus, if $r$ is raised, $\hat{g}$ rises and social welfare can be increased by lowering $p$ so as to 
restore $\hat{g}$ to its original level. Hence, $r$ in $\left(r_{F}, r_{B}\right)$ cannot be optimal. (8) We now know that $r^{*}$ must either equal $r_{F}$ or $r_{B}$ if $r_{F}<r_{B}$; obviously, if $r_{F}=r_{B}$, then $r^{*}=r_{F}=r_{B}{ }^{24}$

We also prove here the result claimed in the text before Proposition 2 concerning the optimality of the fine for the offense, that $f^{*}=w_{O}$. To demonstrate this, suppose otherwise, that $f$ $<w_{O}$. There are two cases to consider. First assume that $r^{*}=r_{F} \leq r_{B}$. Since framing is deterred, $\hat{g}=z_{O}$, which clearly is increasing in $f$ regardless of which side of the min expression in (22) applies. Hence, if $f$ is raised, $\hat{g}$ rises, so that by lowering $p, \hat{g}$ can be restored to its original level and enforcement costs can be saved, increasing social welfare. It must be, therefore, that $f=w_{O}$ is optimal in this case. Now assume that $r^{*}=r_{B}>r_{F}$. Because bribery is deterred but extortion occurs ( since $\left.r^{*}=r_{B}<r_{E}\right), \hat{g}=p f-z_{I}$, where $z_{I}$ is given by the right-hand side of the min expression in (23). The derivative of $\hat{g}$ with respect to $f$ then is $p(1-\lambda)>0$, so by essentially the argument just given, $f=w_{O}$ must be optimal in this case as well.

We briefly discuss here the intuition behind the results in Proposition 2. As noted in the proof, parts (a), (b), and (c) were explained above.

That the fines for bribery and framing are maximal, the claim of part (d), follows from the type of argument associated with Becker — otherwise they could be raised and enforcement effort lowered without affecting deterrence.

Part (e), concerning the optimal probability of detecting bribery $q_{B}{ }^{*}$, is explained as

\footnotetext{
${ }^{24}$ The outcome that $r_{F}=r_{B}$ would tend to occur when the cost of raising $r_{F}=q_{F} f_{E F} /\left(1-q_{F}\right)$ is low - that is, when the cost of raising $q_{F}$ is low. To see why, suppose that $r^{*}=r_{F}$ and $r_{F}<r_{B}$. Then the threat to frame is not credible, but bribery occurs. If it were costless to raise $r_{F}$ to $r_{B}$, then it would be desirable to do so, for $r$ could be kept equal to $r_{F}$ in order to deter framing, but by raising $r$ to $r_{B}$, bribery could be deterred as well. Similarly, if $r^{*}=$ $r_{B}$ and $r_{F}<r_{B}$, it is desirable to raise $r_{F}$ to $r^{*}=r_{B}$ in order to make the threat to frame not credible. For analogous reasons, the outcome that $r_{F}=r_{B}$ would tend to occur when the cost of lowering $r_{B}=f-q_{B}\left(f_{O B}+f_{E B}\right)$ is low - that is, when the cost of raising $q_{B}$ is low.
} 
follows. It is clear that $q_{B}{ }^{*}$ cannot exceed $\bar{q}_{B}$ because that probability is sufficient to deter bribery. If $q_{B} *$ is interior, it is determined by a tradeoff: the higher is $q_{B}$, the greater is the expected cost to the offender of engaging in bribery, which reduces the dilution of deterrence due to bribery; yet the higher is $q_{B}$, the higher are enforcement costs. Note that even though bribery occurs when $q_{B} *$ is less than $\bar{q}_{B}$, sanctioning bribery still discourages commission of the offense. For when bribery occurs, an individual's expected payment if he commits the offense is equal to the sum of his expected bribe payment and his expected sanction for bribery, $p[\lambda f+(1-\lambda) r+$ $\left.(1-\lambda) q_{B}\left(f_{O B}+f_{E B}\right)\right]$ (see (22)), which is increasing in $q_{B}$.

The result in part (f) regarding the optimal probability of detecting framing $q_{F} *$ is analogous to that in part (e) about the optimal probability of detecting bribery. Even if framing is not deterred, raising $q_{F}$ may be beneficial because a higher $q_{F}$ leads to a lower extortion payment.

The claim of part (g), that extortion should not be sanctioned, is surprising, as we have noted previously, and bears explanation. The essential reason that penalizing extortion is undesirable is that such a policy can have only two effects, each of which is detrimental. On one hand, penalizing extortion might not deter extortion, in which case it would raise the expected payment of innocent individuals (the sum of their extortion payment and any expected fine for participating in an extortion agreement); this effect would weaken deterrence. On the other hand, penalizing extortion might deter it — but then enforcers would frame innocent individuals, which would impose even greater costs on them and weaken deterrence more than extortion would. The intuition that might lead one to think that punishing extortion is desirable is that doing so would deter enforcers from engaging in both extortion and framing. However, that is not the case here, for an enforcer who is deterred from engaging in extortion does not decide to 
do nothing; instead he will frame the innocent individual (because, by assumption, he finds it profitable to do so), which is even worse. In view of the counterintuitive nature of this conclusion, we discuss its robustness in the concluding section.

The explanation of part (h) concerning the optimal reward to the enforcer $r^{*}$ is straightforward given the analysis earlier in this section. A low $r$ can deter framing and extortion by making the threat to frame not credible, but bribery then is encouraged because the enforcer forgoes very little by engaging in bribery rather than turning in an offender. Conversely, a high $r$ can deter bribery but then framing and extortion are encouraged. The optimal reward is either low enough to deter framing or high enough to deter bribery, but some form of corruption occurs regardless of the reward (unless $r^{*}=r_{F}=r_{B}$, in which case all corruption is eliminated).

The numerical example from section 2 also can be used to illustrate the results here. Recall that when corruption occurs but no attempt is made to control it, the optimal fine for the offense $f^{*}$ is $\$ 10,000$, the optimal probability of detecting offenders $p *$ is .11 , the critical gain $\hat{g}$ is $\$ 539$, and social welfare is $-\$ 289$. Now let the cost $c_{B}$ to detect bribery with probability $q_{B}$ be $\$ 1,000 q_{B}{ }^{2}$, the cost $c_{F}$ to detect framing with probability $q_{F}$ be $\$ 1,000 q_{F}^{2}$, and the wealth of enforcers $w_{E}$ be $\$ 10,000$. Then the optimal fine for the offense $f^{*}$ remains, of course, at $\$ 10,000$, and the optimal fines on the offender for bribery, $f_{O B}{ }^{*}$, and on the enforcer for bribery and framing, $f_{E B} *$ and $f_{E F} *$, are also $\$ 10,000$. The optimal probability of detecting offenders $p *$ rises to .12 , the optimal probability of detecting bribery $q_{B} *$ is .10 , the optimal probability of detecting framing $q_{F} *$ is .06 , and the optimal reward $r *$ is $\$ 638$, which is the reward $r_{F}$ that deters framing. Although framing and extortion are prevented, bribery occurs because $r^{*}$ is less than $r_{B}=\$ 8,000$, the reward that deters bribery. The bribe payment is $\$ 7,546$, significantly less than the $\$ 10,000$ 
fine for the offense. This bribe payment, together with the risk of paying a $\$ 10,000$ fine if bribery is detected, results in a critical gain $\hat{g}$ of $\$ 935$, much higher than the critical gain of $\$ 539$ that resulted when corruption was not controlled. As a result of the use of sanctions and rewards to deter framing and reduce the effects of bribery, social welfare rises to $-\$ 175$.

If the parameters in the example were such as to make bribery more significant relative to framing, the optimal solution would involve deterring bribery but not framing and extortion. For instance, suppose that the bargaining power of the enforcer $\lambda$ is .3 instead of .7 (thereby lowering the bribe payment and increasing the dilution of deterrence due to bribery), and that the ratio of the probability that an innocent individual could be framed to the probability that an offender is detected $\theta$ is .1 instead of .3 (thereby making framing and extortion less likely). Then $p^{*}$ is .11, $q_{B} *$ is $.02, q_{F} *$ is .02 , and $r^{*}$ is $\$ 9,600$, equal to $r_{B}$. Bribery is deterred, but enforcers' threats to frame innocent individuals are credible and extortion occurs (because $r_{F}=\$ 204<r^{*}<r_{E}=$ $\$ 10,204)$. The extortion payment is $\$ 9,386$.

\section{Concluding Comments}

In this section, we make several remarks about the assumptions of our analysis and the interpretation of our results.

(a) Risk aversion. One of the implications of our assumption that parties are risk neutral was that optimal sanctions are maximal. If, however, offenders are presumed to be risk averse, then optimal fines for offenses may be substantially lower, in order to reduce the imposition of risk. $^{25}$ Thus, the optimal fine for speeding could be several hundred dollars even though much

\footnotetext{
25 See Polinsky and Shavell (1979), and also Kaplow (1992).
} 
higher fines are feasible. But risk aversion does not necessarily imply that fines for corruption should be less than maximal; notably, if high fines can deter corruption completely, such fines will not actually be imposed and risk will not be borne. More realistically, however, if corruption is not deterred completely, consideration of risk bearing is relevant for the setting of fines for corruption as well as for the offense. Observe, too, that if parties are risk averse, they can be discouraged more easily from engaging in corruption than if they are risk neutral.

(b) The robustness of the conclusion that extortion should not be penalized. The counterintuitive nature of our conclusion that extortion should not be penalized raises the issue of its generality. To address this issue, recall that the conclusion followed from the point that penalizing extortion either raises the expected payment of innocent individuals if extortion is not deterred, or else induces enforcers to frame rather than extort such individuals. Because both effects make innocent individuals worse off, penalizing extortion is undesirable. This conclusion might not hold under different assumptions from the ones we considered. For example, suppose that enforcers have to invest effort to create situations in which they are able to frame individuals (we implicitly assumed that no effort was required). In that case, penalizing extortion might be beneficial because such a policy would lower the return to extortion and thus would reduce enforcers' effort to frame individuals. If this effect is more important than the effect identified in our model, punishing extortion would be socially desirable. A second reason our conclusion might not hold is that innocent individuals may have imperfect information about enforcers' true willingness to frame them (we implicitly assumed they had perfect information). Then an innocent individual may be willing to make an extortion payment even though the enforcer would not be willing to frame him. With respect to such enforcers, deterring extortion would be 
desirable because it would not result in framing, but with respect to enforcers who would proceed to frame the individual, deterring extortion would have the detrimental effect that we identified. ${ }^{26}$ Thus, there are reasons not considered in our model why penalizing extortion may be socially desirable, but these arguments need to be balanced against the point that punishing extortion may make innocent individuals worse off.

(c) Raising fines to offset the deterrence-diluting effects of corruption. A question that naturally arises is whether the deterrence-diluting effects of corruption can be offset by raising the fines on offenders. For example, suppose that the optimal fine would be $\$ 100$ if a fine were always paid when an offender is caught, but that bribery results in a bribe payment equal to $\$ 50$, one half of the fine. Could not the fine on an offender be increased to $\$ 200$, so that the bribe would then be $\$ 100$ and the effective penalty be exactly what is desired? It is not possible in our model to raise the fine to offset corruption because the optimal fine on the offender in the absence of corruption already is maximal (see note 14 above and the corresponding discussion in the text). More generally, however, optimal fines for offenses may not be maximal for a variety of reasons. One reason is the risk aversion of offenders, as we mentioned above. Other reasons derive from consideration of marginal deterrence (applicable when offenders can choose among

\footnotetext{
${ }^{26}$ To see this point more precisely, suppose that there are two groups of enforcers, a majority who would be willing to frame, and a minority who would not (say because they face a higher probability of being caught for framing). Then a latter type of enforcer might masquerade as a former type, and thus be able to extract an extortion payment from an innocent individual. If extortion is then deterred, majority-type enforcers will be led to frame innocent individuals, while minority-type enforcers will neither extort nor frame. The net effect could be socially beneficial. For example, suppose that $\lambda$, the bargaining power of enforcers, is close to 1 . Then innocent individuals who are framed by majority-type enforcers will not be much worse off than if they had been extorted (the enforcer would have already been extracting most of the surplus from them through extortion). But innocent individuals who would have been extorted by minority-type enforcers are significantly better off. They now pay nothing. Hence, social welfare could rise, especially if the number of minority-type enforcers is relatively large. But if $\lambda$ is not close to 1 , or if the minority-type group is very small, then punishing extortion would tend to be socially undesirable, essentially for the reasons we gave.
} 
acts having varying levels of harm), and from consideration of the general nature of law enforcement (applicable when the probabilities of detecting different harmful acts are affected by a common investment in enforcement). ${ }^{27}$ When optimal fines are not maximal for these or other reasons, then raising the fine for the offense can at least partially counter the deterrence-diluting effects of corruption. ${ }^{28}$ This does not necessarily mean, however, that corruption is socially irrelevant; the reasons why optimal fines may not be maximal often imply that corruption remains socially undesirable even if the fine can be raised to offset the deterrence-diluting effects of corruption. For example, if individuals are risk averse, innocent individuals who make extortion payments, or who are framed and pay fines, still bear risk as a result of corruption.

(d) Other effects of rewards to enforcers. In our analysis we emphasized that the payment of rewards to enforcers can reduce or eliminate the problem of bribery, but that such payments encourage framing and extortion. There are other effects of rewards that should be mentioned. First, rewarding enforcers will influence their enforcement effort. On one hand, rewards may better motivate enforcers to catch offenders, thereby lowering the social cost of enforcement. On the other hand, enforcers may be led to devote excessive effort to catch offenders because each enforcer will ignore the fact that his effort to catch an offender will reduce the chance that other enforcers will catch that offender (analogous to the familiar point about overfishing from a common pool). ${ }^{29}$ Moreover, paying rewards to enforcers may distort their allocation of time to

\footnotetext{
${ }^{27}$ For a brief explanation of why optimal fines might not be maximal when marginal deterrence and general enforcement are taken into account, see Polinsky and Shavell (2000, pp. 62-64).

${ }^{28}$ However, even then it might not be desirable to raise the fine. If individuals differ in their opportunities or incentives to engage in bribery, raising the fine for the offense may distort the behavior of individuals who do not engage in bribery (although it improves the incentives of those who do engage in bribery).

${ }^{29}$ See generally Landes and Posner (1975), Polinsky (1980), and Mookherjee and Png (1997).
} 
tasks: an enforcer will tend to underinvest in tasks that aid enforcement generally but that will not result in his receiving personal credit leading to a reward to him. ${ }^{30}$ Second, the payment of rewards constitutes a risky form of compensation of enforcers, resulting in an increase in public expense because the expected wage will have to rise to compensate enforcers for bearing risk. The disadvantages of rewards mentioned here, together with the problem of framing and extortion that we studied, help to explain why, in practice, rewards to enforcers are not used in a substantial way (although enforcers are rewarded to some extent for catching violators, notably through enhanced promotion possibilities).

(e) Enforcers' wages as a policy instrument. We assumed that the maximum fine that could be imposed on an enforcer for bribery, framing, or extortion was fixed and equal to the enforcer's wealth. But the state could increase the maximum penalty by paying enforcers higher wages (that is, "efficiency" wages). Then they would have more to lose if punished for corrupt behavior and denied future work. Thus, the wage payment can be used as a policy instrument to discourage corruption. It may be worthwhile for the state to raise enforcers' wages for this reason, especially if it is costly to raise the probability of detecting corruption. There is, however, a social cost to the state of paying enforcers more than the wage necessary to attract them - the distortions caused by the additional taxes needed to make such payments.

\section{Acknowledgments}

\footnotetext{
${ }^{30}$ For example, a police officer might not want to expend effort to gather and communicate information helpful to the entire enforcement organization; or the officer might not want to assist a fellow officer with an investigation if that officer would collect the reward and not pay him for his assistance. These examples reflect the point developed by Holmstrom and Milgrom (1991) that using only particular components of an agent's output (here the number of violators that an agent himself catches) can undesirably skew his effort. As a result, it may not be desirable to use these indicators of output, or to use them in a limited way.
} 
Polinsky's research was supported by the Center for Advanced Study in the Behavioral Sciences (through National Science Foundation grant \#SBR-960123) and the John M. Olin Program in Law and Economics at Stanford Law School. Shavell's research was supported by the John M. Olin Center for Law, Economics, and Business at Harvard Law School. We are grateful to Jennifer Arlen, Lucian Bebchuk, Omri Ben-Shahar, Robert Cooter, Louis Kaplow, Mathew McCubbins, Andrei Shleifer, Eric Talley, Donald Wittman, and two anonymous referees for comments, and to Katie Carman, Steven Mitby, and Kassra Nassiri for able research assistance. 


\section{References}

Bardhan, P., 1997. Corruption and development: a review of issues. Journal of Economic Literature 35 ( 3), 1320-1346.

Basu, K., Bhattacharya, S., Mishra, A., 1992. Notes on bribery and the control of corruption. Journal of Public Economics 48 (3), 349-359.

Becker, G.S., 1968. Crime and punishment: an economic approach. Journal of Political Economy 76 (2), 169-217.

Becker, G.S., Stigler, G.J., 1974. Law enforcement, malfeasance, and compensation of enforcers. Journal of Legal Studies 3 (1), 1-18.

Bowles, R., Garoupa, N., 1997. Casual police corruption and the economics of crime. International Review of Law and Economics 17 (1), 75-87.

Hindriks, J., Keen, M., Muthoo, A., 1999. Corruption, extortion and evasion. Journal of Public Economics 74 (3), 395-430.

Holmstrom, B., Milgrom, P., 1991. Multitask principal-agent analyses: incentive contracts, asset ownership, and job design. Journal of Law, Economics, \& Organization 7, 24-52.

Kaplow, L., 1992. The optimal probability and magnitude of fines for acts that definitely are undesirable. International Review of Law and Economics 12 (1), 3-11.

Klitgaard, R., 1988. Controlling Corruption, University of California Press, Berkeley.

Kofman, F., Lawarrée, J., 1993. Collusion in hierarchical agency. Econometrica 61 (3), 629656.

Landes, W.M., Posner, R.A., 1975. The private enforcement of law. Journal of Legal Studies 4 (1), 1-46. 
Mookherjee, D., Png, I.P.L., 1995. Corruptible law enforcers: how should they be compensated? Economic Journal 105 (428), 145-159.

Pashigian, B.P., 1975. On the control of crime and bribery. Journal of Legal Studies 4 (2), 311 326.

Png, I.P.L., 1986. Optimal subsidies and damages in the presence of judicial error. International Review of Law and Economics 6, 101-05.

Polinsky, A.M., 1980. Private versus public enforcement of fines. Journal of Legal Studies 9 (1), 105-127.

Polinsky, A.M., Shavell, S., 1979. The optimal tradeoff between the probability and magnitude of fines. American Economic Review 69 (5), 880-891.

Polinsky, A.M., Shavell, S., 2000. The economic theory of public enforcement of law. Journal of Economic Literature 38 (1), 45-76.

Rose-Ackerman, S., 1999. Corruption and Government: Causes, Consequences, and Reform, Cambridge University Press, Cambridge.

Shleifer, A., Vishny, R.W., 1993. Corruption. Quarterly Journal of Economics 108 (3), 599-617.

Tirole, J., 1986. Hierarchies and bureaucracies: on the role of collusion in organizations. Journal of Law, Economics, and Organization 2 (2), 181-214. 